\title{
Modelling and Simulation of Volume Controlled Mechanical Ventilation System
}

\author{
Yan Shi, ${ }^{1,2}$ Shuai Ren, ${ }^{1}$ Maolin Cai, ${ }^{1}$ and Weiqing $X u^{1}$ \\ ${ }^{1}$ School of Automation Science and Electrical Engineering, Beihang University, Beijing 100191, China \\ ${ }^{2}$ Department of Mechanical Engineering, University of Bath, Bath BA2 7AY, UK \\ Correspondence should be addressed to Weiqing Xu; xuweiqing2010@gmail.com
}

Received 6 May 2014; Revised 10 June 2014; Accepted 12 June 2014; Published 1 July 2014

Academic Editor: Yuxin Zhao

Copyright (c) 2014 Yan Shi et al. This is an open access article distributed under the Creative Commons Attribution License, which permits unrestricted use, distribution, and reproduction in any medium, provided the original work is properly cited.

\begin{abstract}
Volume controlled mechanical ventilation system is a typical time-delay system, which is applied to ventilate patients who cannot breathe adequately on their own. To illustrate the influences of key parameters of the ventilator on the dynamics of the ventilated respiratory system, this paper firstly derived a new mathematical model of the ventilation system; secondly, simulation and experimental results are compared to verify the mathematical model; lastly, the influences of key parameters of ventilator on the dynamics of the ventilated respiratory system are carried out. This study can be helpful in the VCV ventilation treatment and respiratory diagnostics.
\end{abstract}

\section{Introduction}

Mechanical ventilation is an important treatment which is usually utilized to ventilate patients who cannot breathe adequately on their own [1]. As an alternative mode of ventilation, volume controlled ventilation (VCV) can be used in respiratory failure [2].

As well known, the VCV ventilation system is a typical time-delay system. Due to the respiratory resistance and compliance, the dynamics of the ventilated lung always lags behind the output dynamics of the VCV ventilator. Time delays are usually the main causes of instability and poor performance of system [3-6]; therefore, in clinical application, the dynamics of the outlet of the ventilator is monitored to estimate the dynamics of the patient's respiratory system. So the precision of the estimation is limited [7].

Because the dynamics of the ventilated lung is influenced by the parameters of the VCV ventilator, in order to lay a foundation for the VCV ventilation treatment, the influences of the VCV ventilator's parameters on the dynamics of the ventilated lung should be illustrated. But the dynamics of the ventilated lung cannot be measured directly and precisely. Therefore, a simulation study of the ventilation system (including a VCV ventilator and a patient's respiratory system) is needed.
In the present modelling and simulation studies of the mechanical ventilation system, the system is commonly considered as an electrical system [8-11]. However, these models have many serious shortcomings, which limit their versatility and applicability [10, 12-15].

In this paper, in order to improve the versatility and applicability of the mathematical models of the VCV ventilation systems, the VCV ventilation system is considered as an equivalent pneumatic system. Then a new mathematical model of the VCV ventilation system can be derived.

Furthermore, through the simulation study on the VCV ventilation system, its dynamic characteristics can be obtained. Simulation and experimental results [7] are compared to verify the mathematical model.

Lastly, in order to provide guidance for the VCV ventilation treatment, influences of key parameters of the VCV ventilator on the dynamics of the ventilated respiratory system are studied.

\section{Methods of Study on the VCV Ventilation System}

2.1. Introduction of VCV Ventilation System. A VCV ventilation system is composed of a human lung, a respiratory 


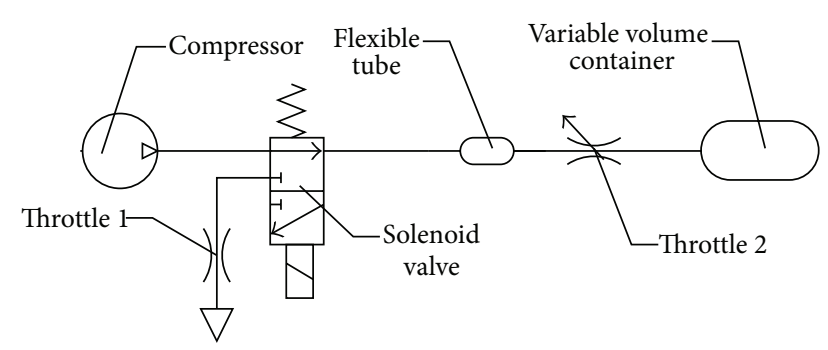

FIGURE 1: Structure of the equivalent pneumatic system.

tract, a flexible tube, and a VCV ventilator. In the inspiration process, positive pressure ventilation (generated by the ventilator) is utilized to force airflow into the lung. In the expiration process, due to the elasticity of the lung, air is expelled to the atmosphere through an exhalation valve, which is embedded in the ventilator. Therefore, according to their functions, the ventilator can be regarded as an air compressor, the exhalation valve can be considered as a throttle, and the human lung can be regarded as a variable volume container. The minimum inner diameter of the respiratory tracts is influenced by the secretion deposition, so the respiratory tract can be considered as a throttle.

Therefore, the VCV ventilation system can be regarded as a pneumatic system, as shown in Figure 1. The compressor, the container, and throttles 1 and 2 represent the ventilator, the human lung, the exhalation valve, and the respiratory tract, respectively. The effective area of the exhalation valve and respiratory tract are represented by $A_{\mathrm{ev}}$ and $A_{\mathrm{rt}}$, respectively.

When the variable volume container is ventilated, the flexible tube and the compressor are connected with the solenoid valve. Then the compressed air, output from the compressor, flows into the variable container through the solenoid valve, flexible tube, and throttle 2. During the expiration, the flexible tube and throttle 1 are connected with the solenoid valve. Then the compressed air, output from the variable volume container, flows into the atmosphere through the solenoid valve, flexible tube, and throttles 2 and 1.

Therefore, the versatility and applicability of the mathematical models of the VCV ventilation systems are better than the mathematical models when the VCV ventilation system is commonly considered as an electrical system.

\subsection{Modeling of Mechanical Ventilation System}

2.2.1. Flow Equations. To facilitate research, the following assumptions are made:

(1) air of the system follows all ideal gas laws;

(2) the dynamic process is a quasi-balanced process;

(3) there is no air leakage during the working process.
(1) Output Flow of the VCV Ventilator. According to the working principle of the VCV ventilation, the output flow of the VCV ventilator can be given as

$$
\begin{gathered}
Q_{\mathrm{vo}}= \begin{cases}Q_{T} & V_{\mathrm{vo}}<V_{T}, \\
0 & V_{\mathrm{vo}} \geq V_{T},\end{cases} \\
Q_{t}=\frac{V_{T}}{T_{\mathrm{vo}}}=\frac{V_{T}}{T_{i}-T_{p}} .
\end{gathered}
$$

(2) Air Flow through the Exhalation Valve and the Endotracheal Tube. When air flows through the exhalation valve and the endotracheal tube, their mass flow can be calculated by the equation when air flows through the LAVAL nozzle. As the pressure of the studied ventilation system is in the range of $0 \sim 40 \mathrm{~cm} \mathrm{H}_{2} \mathrm{O}$, the ratio of the downstream pressure to the upstream pressure is always bigger than 0.528 ; the air flow through the exhalation valve and the respiratory tract can be given by

$$
Q_{\mathrm{ev}}=\frac{A_{\mathrm{ev}} p_{t}}{\rho_{a} \sqrt{\theta}} \sqrt{\frac{2 \kappa}{\kappa-1} \frac{1}{R}\left[\left(\frac{p_{a}}{p_{t}}\right)^{2 / \kappa}-\left(\frac{p_{a}}{p_{t}}\right)^{(\kappa+1) / k}\right]},
$$

$Q_{\mathrm{rt}}$

$$
= \begin{cases}\frac{A_{\mathrm{rt}} p_{t}}{\rho_{a} \sqrt{\theta}} \sqrt{\frac{2 \kappa}{\kappa-1} \frac{1}{R}\left[\left(\frac{p_{l}}{p_{t}}\right)^{2 / \kappa}-\left(\frac{p_{l}}{p_{t}}\right)^{(\kappa+1) / k}\right]} & p_{t}>p_{l} \\ \frac{A_{\mathrm{rt}} p_{l}}{\rho_{a} \sqrt{\theta}} \sqrt{\frac{2 \kappa}{\kappa-1} \frac{1}{R}\left[\left(\frac{p_{t}}{p_{l}}\right)^{2 / \kappa}-\left(\frac{p_{t}}{p_{l}}\right)^{(\kappa+1) / k}\right]} & p_{l} \leq p_{t} .\end{cases}
$$

2.2.2. Pressure Equation. The VCV ventilation system can be considered as an open thermodynamic system, and its work can be regarded as an isothermal process. The differential expression of the Clapeyron equation $(P V=m R \theta)$ is given by

$$
\frac{d p}{d t}=\frac{1}{V} R \theta q-\frac{m R \theta}{V^{2}} \frac{d V}{d t} .
$$

After transformation of (3), the pressure in the flexible tube and the ventilated lung can be given by

$$
\begin{aligned}
& \frac{d p_{t}}{d t}=\frac{R \theta q V_{t}}{V_{t}^{2}+C m R \theta}, \\
& \frac{d p_{l}}{d t}=\frac{R \theta q V_{l}}{V_{l}^{2}+C m R \theta} .
\end{aligned}
$$

2.2.3. Volume Equation. The compliance $C$ of the lung can be described as [16]

$$
C_{l}=\frac{d V_{l}}{d p_{l}}
$$

Then, the volume of the lung can be calculated by the following formula:

$$
d V_{l}=C_{l} d p_{l}
$$



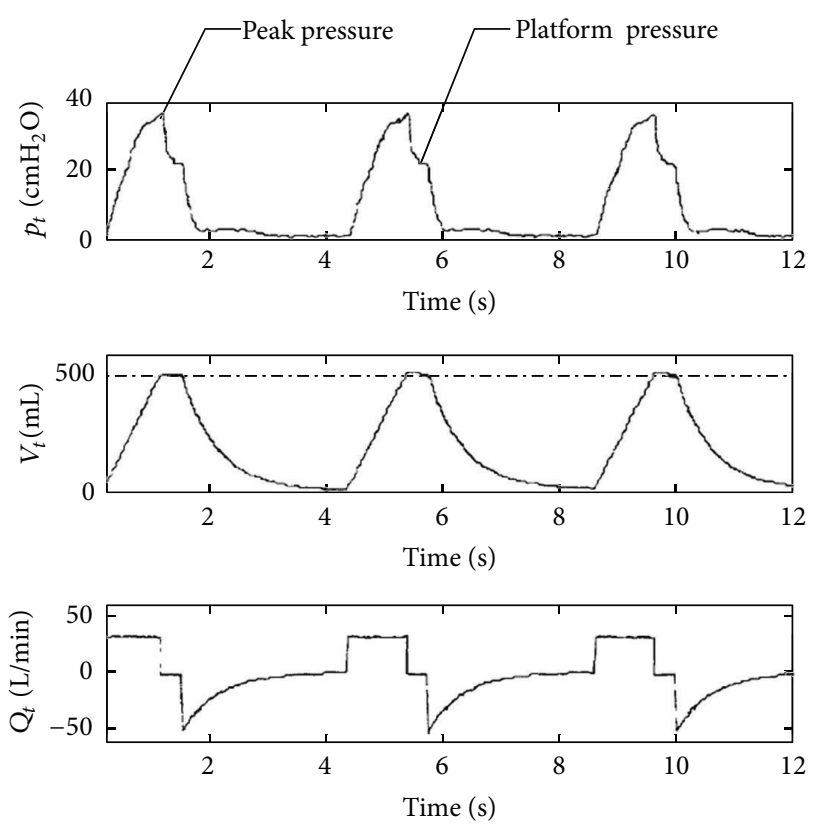

FIGURE 2: Experimental results in the reference.

\section{Study on the Dynamics of the VCV Ventilation System}

3.1. Experimental Verification of the Mathematical Model. In [7], an experimental study on a VCV ventilation system was carried out; $T_{i}, T_{p}, T_{e}$, and $V_{T}$ are set to $1.6 \mathrm{~s}, 0.4 \mathrm{~s}, 2.7 \mathrm{~s}$, and $500 \mathrm{~mL}$. The compliance of the flexible tube and that of the ventilated lung are $4 \mathrm{~mL} / \mathrm{cmH}_{2} \mathrm{O}$ and $25.7 \mathrm{~mL} / \mathrm{cmH}_{2} \mathrm{O}$. The effective areas of the exhalation valve and respiratory tract are $16 \mathrm{~mm}^{2}$ and $9 \mathrm{~mm}^{2}$. The experimental VCV ventilation system [7] was simulated with the mathematical model, which is coded in an S-function of Matlab/simulink. The experimental and the simulation results are shown in Figures 2 and 3 .

The curves of the pressure $\left(p_{t}\right)$ in the flexible tube, the pressure $\left(p_{l}\right)$ in the lung, the volume $\left(V_{t}\right)$ of the air which flows through the inlet of the flexible tube, the volume $\left(V_{l}\right)$ of the air which flows into and out of the lung, the air flow $\left(Q_{t}\right)$ through the inlet of the flexible tube, and the air flow $\left(Q_{l}\right)$ into and out of the lung are shown in Figures 2 and 3.

As can be seen in Figures 2 and 3, it is obvious that

(1) the simulation results are consistent with the experimental results, and this verifies the mathematical model; therefore, the mathematical model can be used in the study on the VCV system;

(2) as can be seen, the air pressure in the lung always lags behind the pressure in the flexible tube and that is why the pressure in the lung cannot be maintained precisely; the main reason of the difference between the simulation and the experimental results is that the respiratory resistance and compliance block the fluctuation of the pressure in the lung simulator.
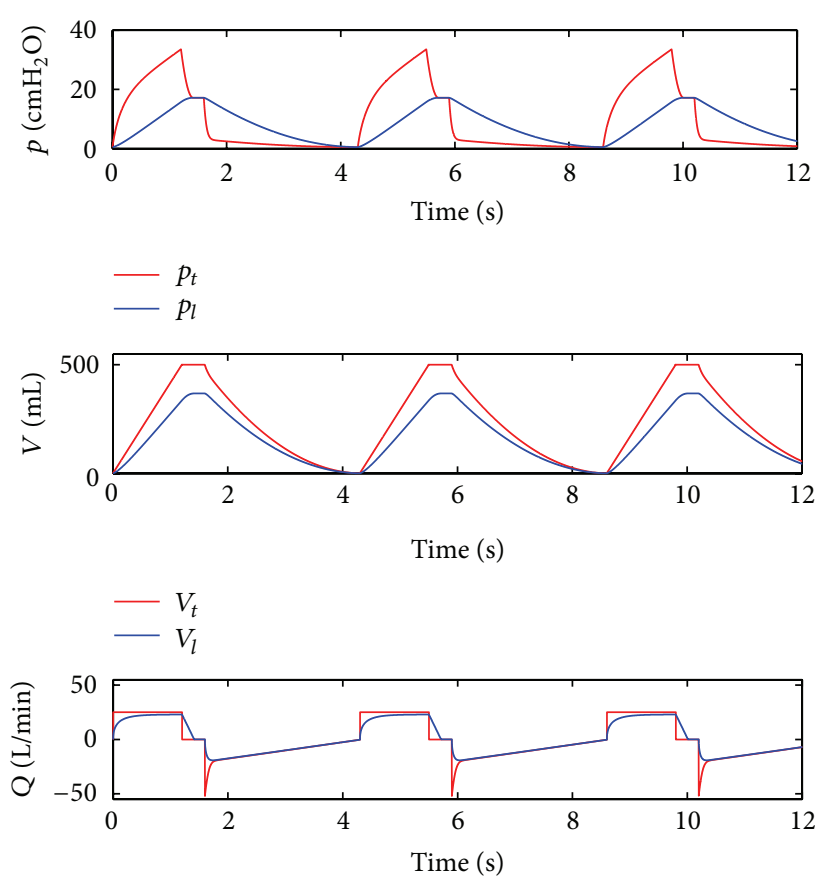

$$
\begin{array}{r}
-Q_{t} \\
-Q_{l}
\end{array}
$$

FIGURE 3: Simulation results.

3.2. Influence of the Key Parameters of the VCV Ventilator on the Dynamics. The key parameters of the VCV ventilator consist of its structure parameters $\left(A_{\mathrm{ev}}\right)$ and its settings (such as $V_{T}$ and $T_{\text {vo }}$ ).

According to the simulation above, each parameter can be changed for comparison while all other parameters are kept constant, and the simulation results for varying each parameter are illustrated in Figures 4, 5, and 6.

3.2.1. Influence of the Effective Area $\left(A_{e v}\right)$ of the Exhalation Valve. The effective area $\left(A_{\mathrm{ev}}\right)$ of the exhalation valve is set to $6 \mathrm{~mm}^{2}, 8 \mathrm{~mm}^{2}, 12 \mathrm{~mm}^{2}, 16 \mathrm{~mm}^{2}, 20 \mathrm{~mm}^{2}$, and $24 \mathrm{~mm}^{2}$, and the simulation results are illustrated in Figure 4.

As shown in Figure 4, it can be seen that only the exhaust flows of the flexible tube and the ventilated lung are influenced by the effective area $\left(A_{\mathrm{ev}}\right)$ of the exhalation valve. With an increase in the effective area $\left(A_{\mathrm{ev}}\right)$ of the exhalation valve, the maximum exhaust air flow of the flexible tube increases proportionally, but the maximum exhaust air flow of the lung increases more and more slowly.

3.2.2. Influence of the Tidal Volume $\left(V_{T}\right)$ of the Ventilator. The tidal volume $\left(V_{T}\right)$ of the ventilator is set to $200 \mathrm{~mL}, 300 \mathrm{~mL}$, $400 \mathrm{~mL}, 500 \mathrm{~mL}, 600 \mathrm{~mL}$, and $700 \mathrm{~mL}$, and the simulation results are illustrated in Figure 5.

As shown in Figure 5, it can be seen that with an increase in the tidal volume $\left(V_{T}\right)$ of the ventilator, the peak pressures in the flexible tube and the lung increase proportionally, but when the tidal volume $\left(V_{T}\right)$ is larger than $600 \mathrm{~mL}$, the peak pressure in the lung increases slowly. 

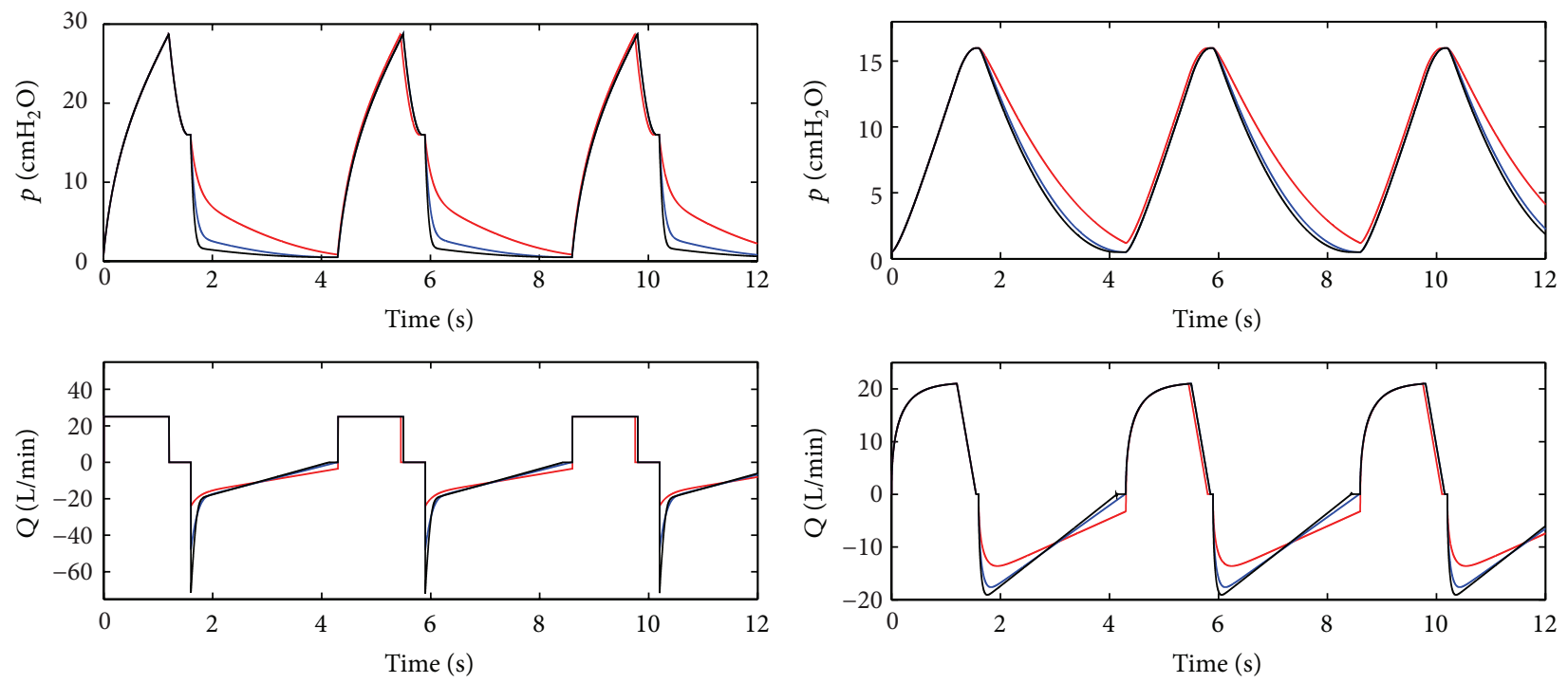

$\begin{aligned}-A_{\mathrm{ev}} & =8 \\ -A_{\mathrm{ev}} & =16 \\ -A_{\mathrm{ev}} & =24\end{aligned}$

(a) Influences of the $A_{\mathrm{ev}}$ on the dynamics of the tube

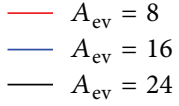

(b) Influences of the $A_{\text {ev }}$ on the dynamics of the lung
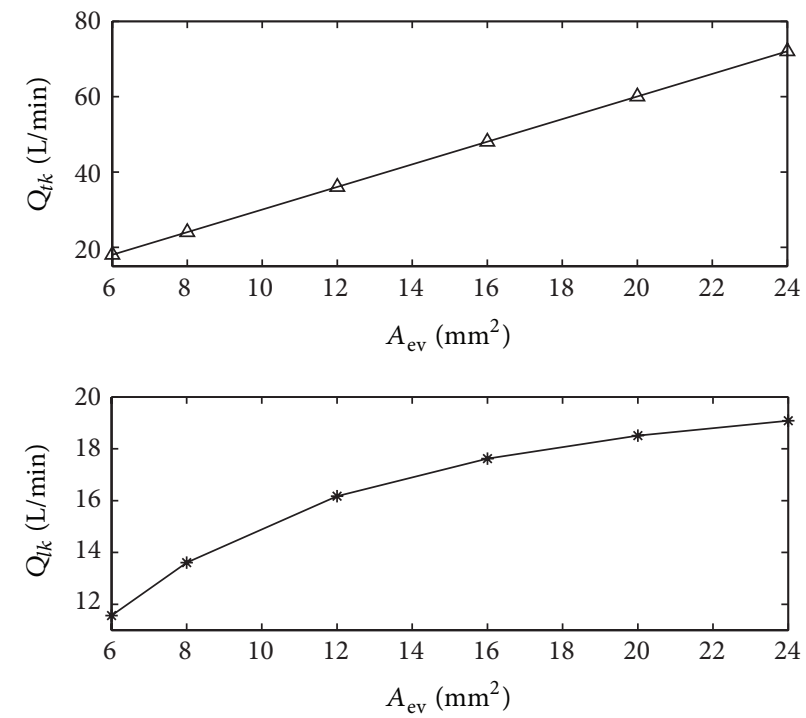

(c) Relationship between the $Q_{t k}$ and $Q_{l k}$ and the $A_{\mathrm{ev}}$

FIgURE 4: Influences of the effective area of the exhalation valve.

When the tidal volume $\left(V_{T}\right)$ is smaller than $600 \mathrm{~mL}$, the maximum exhaust air flows of the flexible tube and the lung proportionally increase with an increase in the tidal volume $\left(V_{T}\right)$. When the tidal volume $\left(V_{T}\right)$ is larger than $600 \mathrm{~mL}$, the maximum exhaust flow of the flexible tube increases faster and faster; however, the maximum exhaust flow of the lung increases more and more slowly.

\subsubsection{Influence of the Exhaust Time $\left(T_{v_{0}}\right)$ of the Ventilator.} The exhaust time $\left(T_{\mathrm{vo}}\right)$ of the ventilator is set to $1 \mathrm{~s}, 1.2 \mathrm{~s}, 1.4 \mathrm{~s}$, $1.6 \mathrm{~s}, 1.8 \mathrm{~s}$, and $2 \mathrm{~s}$, and the simulation results are illustrated in Figure 6.
As shown in Figure 6, it can be seen that when the exhaust time $\left(T_{\mathrm{vo}}\right)$ of the ventilator is smaller than $1.6 \mathrm{~s}$, the platform of the pressure in the tube may not appear.

Furthermore, with an increase in the exhaust time $\left(T_{\mathrm{vo}}\right)$ of the ventilator, the peak pressure in the lung increases. And when the exhaust time $\left(T_{\mathrm{vo}}\right)$ of the ventilator is longer than $1.6 \mathrm{~s}$, the peak pressure in the lung is constant.

Moreover, with an increase in the exhaust time $\left(T_{\mathrm{vo}}\right)$ of the ventilator, the maximum flow of the flexible tube increases and it peaks when the exhaust time $\left(T_{\mathrm{vo}}\right)$ of the ventilator is $1.2 \mathrm{~s}$. After the peak, the maximum flow of the flexible tube falls. When the exhaust time $\left(T_{\mathrm{vo}}\right)$ of the ventilator is $1.6 \mathrm{~s}$, 

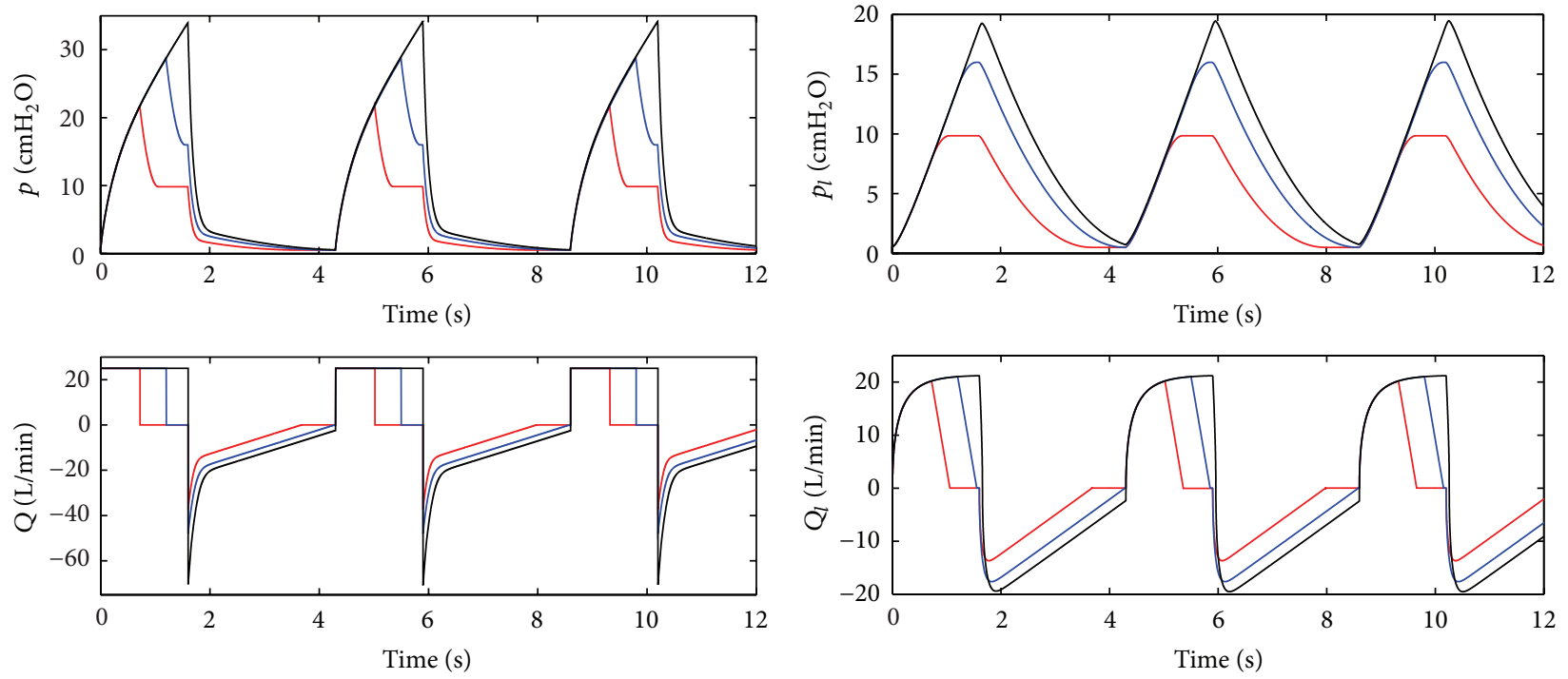

$\begin{aligned}- & V_{T}=300 \\ - & V_{T}=500 \\ -V_{T} & =700\end{aligned}$

(a) Influences of the $V_{T}$ on the dynamics of the tube
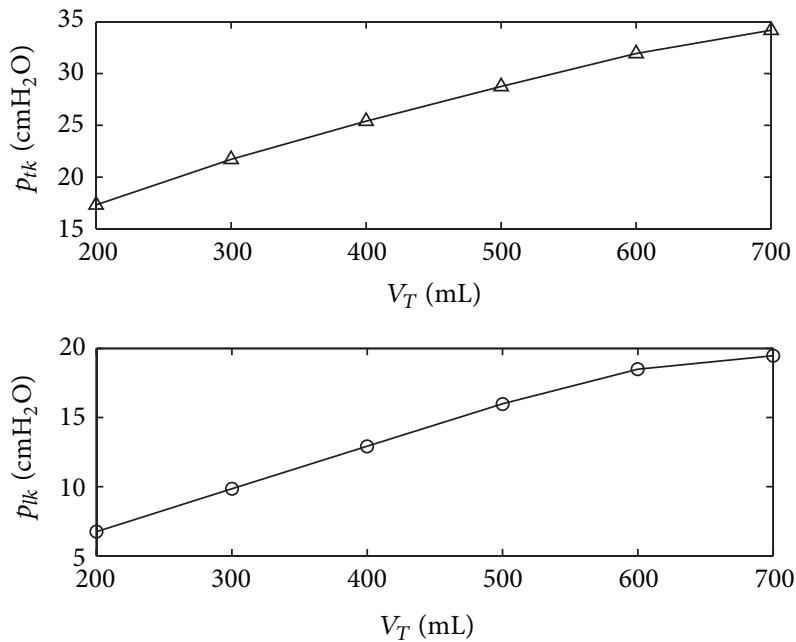

(c) Relationship between the $p_{t k}$ and $p_{l k}$ and the $V_{T}$

$$
\begin{aligned}
-V_{T} & =300 \\
- & V_{T}=500 \\
-V_{T} & =700
\end{aligned}
$$

(b) Influences of the $V_{T}$ on the dynamics of the lung
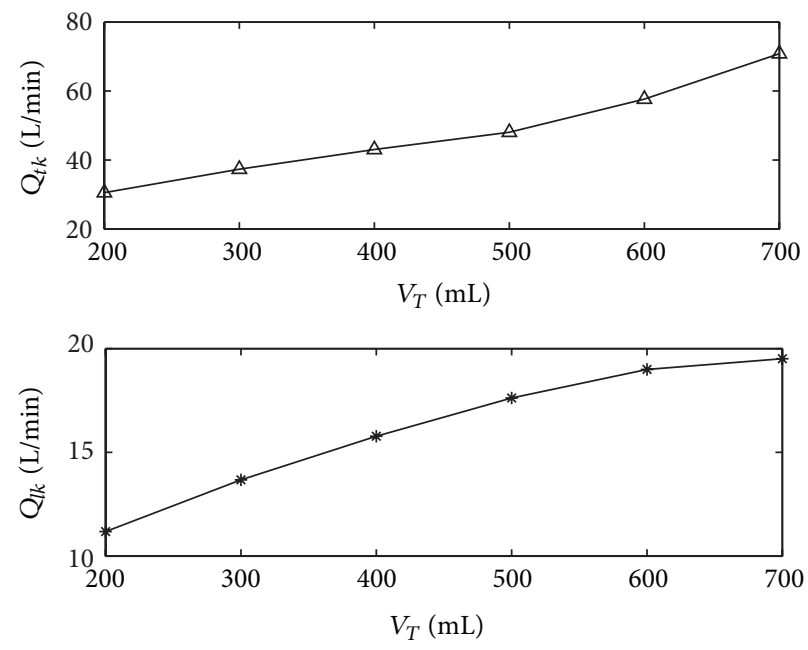

(d) Relationship between the $Q_{t k}$ and $Q_{l k}$ and the $V_{T}$

Figure 5: Influences of the tidal volume $\left(V_{T}\right)$ of the ventilator.

the maximum flow of the flexible tube reaches its bottom; after that it keeps constant.

Finally, when the exhaust time $\left(T_{\mathrm{vo}}\right)$ of the ventilator is shorter than $1.6 \mathrm{~s}$, the maximum flow of the lung increases with an increase in the exhaust time $\left(T_{\mathrm{vo}}\right)$. When the exhaust time $\left(T_{\mathrm{vo}}\right)$ of the ventilator is longer than $1.6 \mathrm{~s}$, the maximum flow is constant.

\section{Conclusions}

In this paper, the VCV ventilation system was compared to a pneumatic system, and then a new mathematical model of the VCV ventilation system was derived. In order to verify the mathematical model, an experimental prototype VCV ventilation system was simulated mathematically. Simulation studies on the influences of the key parameters of the VCV ventilator on the dynamics of the ventilated respiratory system were done, and the conclusions of this study are summarized as follows.

(1) The simulation results are consistent with the experimental results, which verify the mathematical model. Therefore, the mathematical model can be used in the study on the VCV system, and it has better versatility and applicability.

(2) With an increase in the effective area of the exhalation valve, the maximum exhaust air flow of the lung increases more and more slowly. 

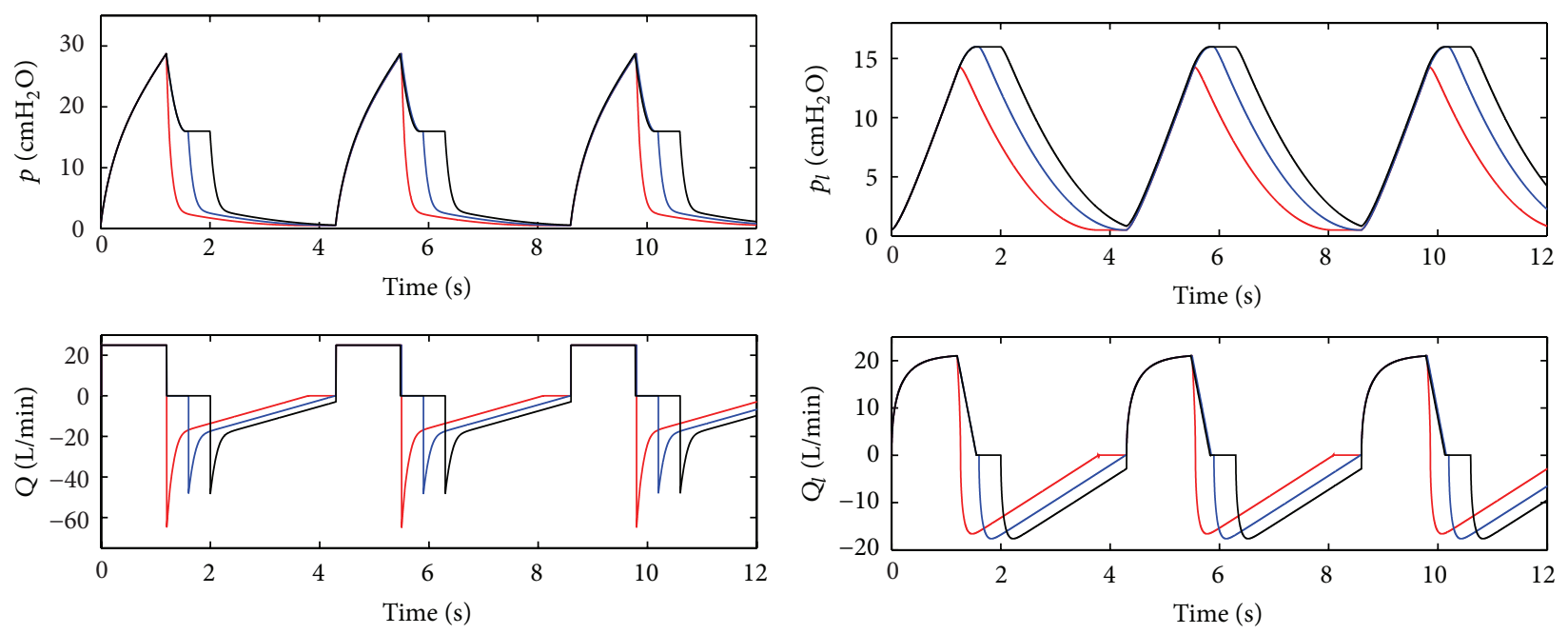

$-T_{\mathrm{vo}}=1.2$
$-T_{\mathrm{vo}}=1.6$
$-T_{\mathrm{vo}}=2$

$\begin{aligned}-T_{\mathrm{vo}} & =1.2 \\ -T_{\mathrm{vo}} & =1.6 \\ -T_{\mathrm{vo}} & =2\end{aligned}$

(a) Influences of the $T_{\text {vo }}$ on the dynamics of the tube

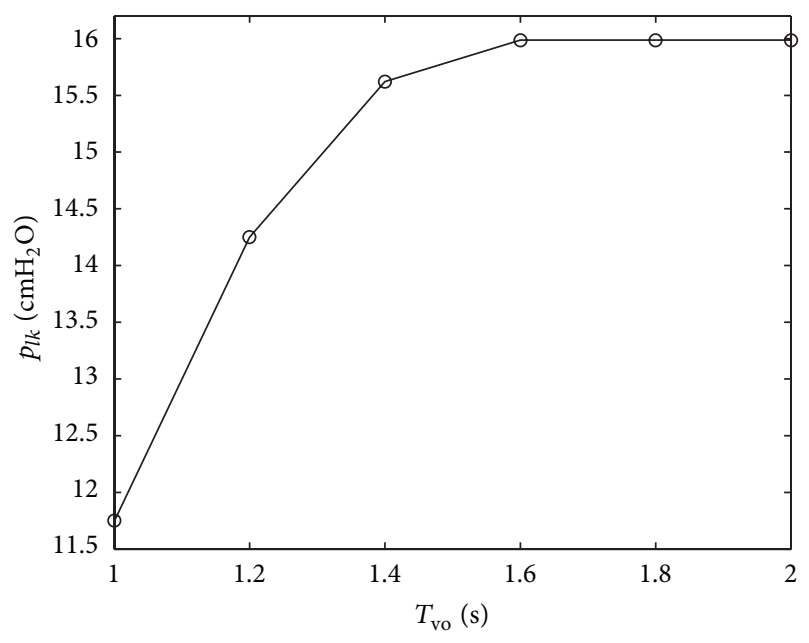

(c) Relationship between the $p_{l k}$ and the $T_{\mathrm{vo}}$ (b) Influences of the $T_{\mathrm{vo}}$ on the dynamics of the lung
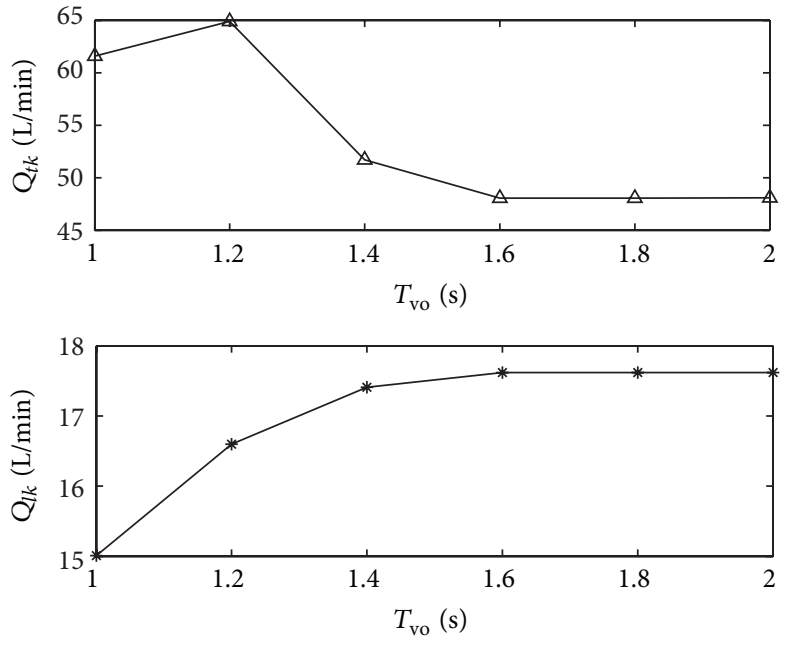

(d) Relationship between the $Q_{t k}$ and $Q_{l k}$ and the $T_{\mathrm{vo}}$

FIGURE 6: Influences of the exhaust time $\left(T_{\mathrm{vo}}\right)$ of the ventilator.

(3) With an increase in the tidal volume of the ventilator, the peak pressure in the lung increases proportionally, but when the tidal volume is larger than $600 \mathrm{~mL}$, the peak pressure in the lung increases slowly.

(4) When the tidal volume is smaller than $600 \mathrm{~mL}$, the maximum exhaust air flow of the lung proportionally increases with an increase in the tidal volume. When the tidal volume is larger than $600 \mathrm{~mL}$, the maximum exhaust flow of the lung increases more and more slowly.

(5) When the exhaust time of the ventilator is shorter than $1.6 \mathrm{~s}$, the maximum flow of the lung increases with an increase in the exhaust time. When the exhaust time of the ventilator is longer than $1.6 \mathrm{~s}$, the maximum flow is constant.
This study can be of use in the VCV ventilation treatment and respiratory diagnostics. In the future, the clinical study will be done to verify the conclusions.

\section{Nomenclature}

A: Equivalent effective area $\left[\mathrm{m}^{2}\right]$

$C$ : Respiratory compliance $\left[\mathrm{L} / \mathrm{cmH}_{2} \mathrm{O}\right]$

$m$ : Mass $[\mathrm{kg}]$

$p:$ Pressure $[\mathrm{Pa}]$

q: Air mass flow $[\mathrm{kg} / \mathrm{s}]$

Q: Air volume flow $\left[\mathrm{m}^{3} / \mathrm{s}\right]$

$R:$ Gas constant $=287[\mathrm{~J} /(\mathrm{kg} \cdot \mathrm{K})]$

$t:$ Time $[\mathrm{s}]$

$V:$ Volume $\left[\mathrm{m}^{3}\right]$ 
$\rho:$ Density $\left[\mathrm{kg} / \mathrm{m}^{3}\right]$

$\kappa:$ Specific heat ratio $=1.4$

$\theta$ : Temperature $[\mathrm{K}]$.

\section{Subscripts}

a: The standard reference atmosphere state

ev: Exhalation valve

frc: Functional residual capacity

$i$ : Inspiration/input

$k$ : Peak/maximum

$l$ : $\quad$ Lung

$o$ : Output

p: Platform

rt: Respiratory tract

T: Tidal

$t$ : Tube

$v$ : Ventilator.

\section{Conflict of Interests}

The authors declare that there is no conflict of interests regarding the publication of this paper.

\section{References}

[1] F. T. Tehrani, "A control system for mechanical ventilation of passive and active subjects," Computer Methods and Programs in Biomedicine, vol. 110, no. 3, pp. 511-518, 2013.

[2] L. E. C. de Baerdemaeker, C. van Der Herten, J. M. Gillardin, P. Pattyn, E. P. Mortier, and L. L. Szegedi, "Comparison of volume-controlled and pressure-controlled ventilation during laparoscopic gastric banding in morbidly obese patients," Obesity Surgery, vol. 18, no. 6, pp. 680-685, 2008.

[3] F. Li and X. Zhang, "A delay-dependent bounded real lemma for singular LPV systems with time-variant delay," International Journal of Robust and Nonlinear Control, vol. 22, no. 5, pp. 559574, 2012.

[4] J. K. Hale, Theory of Functional Differential Equations, Springer, New York, NY, USA, 1977.

[5] Y. Kuang, Delay Differential Equations: With Applications in Population Dynamics, Academic Press, Boston, Mass, USA, 1993.

[6] L. Wu, X. Su, and P. Shi, "Sliding mode control with bounded $\mathscr{L}_{2}$ gain performance of Markovian jump singular time-delay systems," Automatica, vol. 48, no. 8, pp. 1929-1933, 2012.

[7] Y. Weiwei, Research on key technologies of ventilation mode based on active servo lung [Ph. D. Thesis], National University of Defense Technology, 2009.

[8] C. Ionescu, E. Derom, and R. de Keyser, "Assessment of respiratory mechanical properties with constant-phase models in healthy and COPD lungs," Computer Methods and Programs in Biomedicine, vol. 97, no. 1, pp. 78-85, 2010.

[9] J. Chmielecki, J. Foo, G. R. Oxnard et al., "Optimization of dosing for EGFR-mutant non-small cell lung cancer with evolutionary cancer modeling," Science Translational Medicine, vol. 3, no. 90, Article ID 90ra59, 2011.

[10] G. Redlarski and J. Jaworski, "A new approach to modeling of selected human respiratory system diseases, directed to computer simulations," Computers in Biology and Medicine, vol. 43, no. 10, pp. 1606-1613, 2013.

[11] B. Diong, M. D. Goldman, and H. Nazeran, "Respiratory impedance values in adults are relatively insensitive to mead model lung compliance and chest wall compliance parameters," in Proceedings of the 26th Southern Biomedical Engineering Conference (SBEC '10), vol. 32 of IFMBE Proceedings, pp. 201-203, College Park, Md, USA, May 2010.

[12] W. Tomalak, Wybrane aspekty badania mechaniki oddychania $i$ modelowania systemu oddechowego przy uzyciu techniki oscylacji wymuszonych [M.S. dissertation], 1998.

[13] J. G. Eyles and R. L. Pimmel, "Estimating respiratory mechanical parameters in parallel compartment models," IEEE Transactions on Biomedical Engineering, vol. 28, no. 4, pp. 313-317, 1981.

[14] B. Diong, M. Goldman, and H. Nazeran, "Respiratory impedance values in adults are relatively insensitive to mead model lung compliance and chest wall compliance parameters," in Proceedings of the 26th Southern Biomedical Engineering Conference (SBEC '10), vol. 32 of IFMBE Proceedings, pp. 201-203, 2010.

[15] G. Avanzolini, P. Barbini, A. Cappello, G. Cevenini, and L. Chiari, "A new approach for tracking respiratory mechanical parameters in real-time," Annals of Biomedical Engineering, vol. 25, no. 1, pp. 154-163, 1997.

[16] N. Jaimchariyatam, R. A. Dweik, R. Kaw, and L. S. Aboussouan, "Polysomnographic determinants of nocturnal hypercapnia in patients with sleep apnea," Journal of Clinical Sleep Medicine, vol. 9, no. 3, pp. 209-215, 2013. 


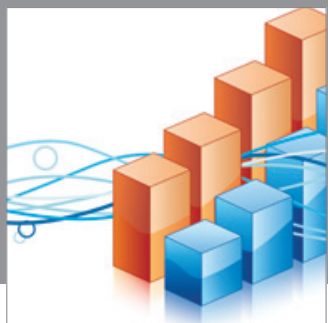

Advances in

Operations Research

mansans

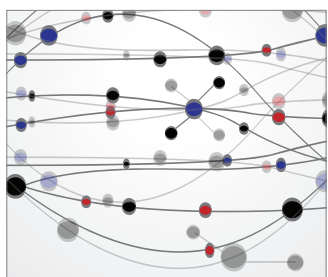

The Scientific World Journal
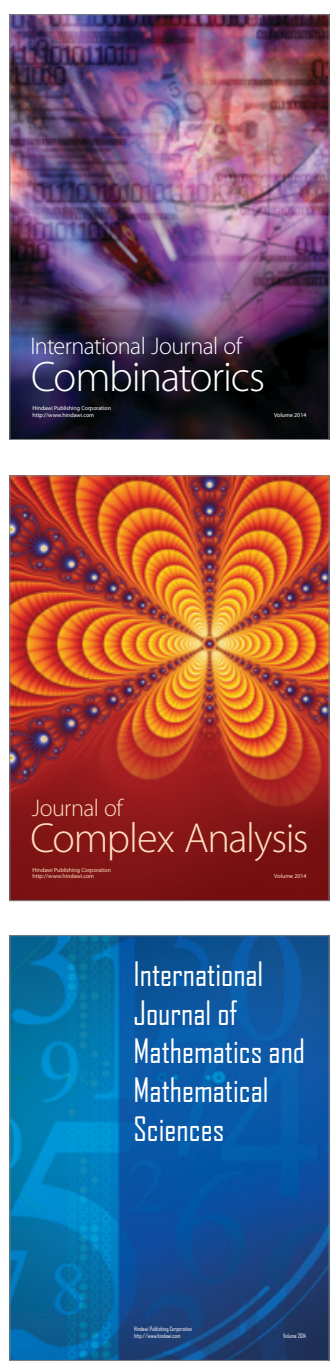
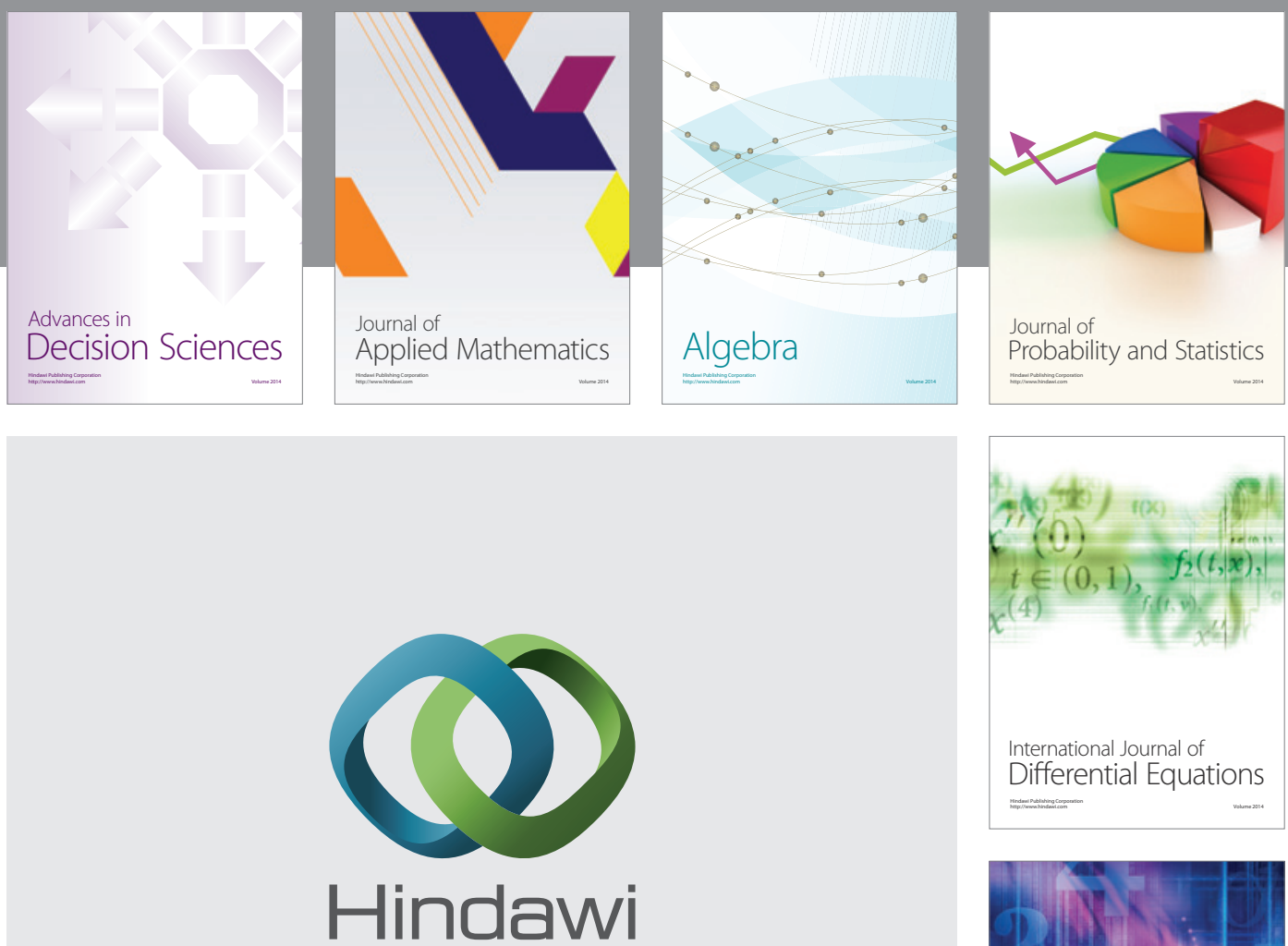

Submit your manuscripts at http://www.hindawi.com
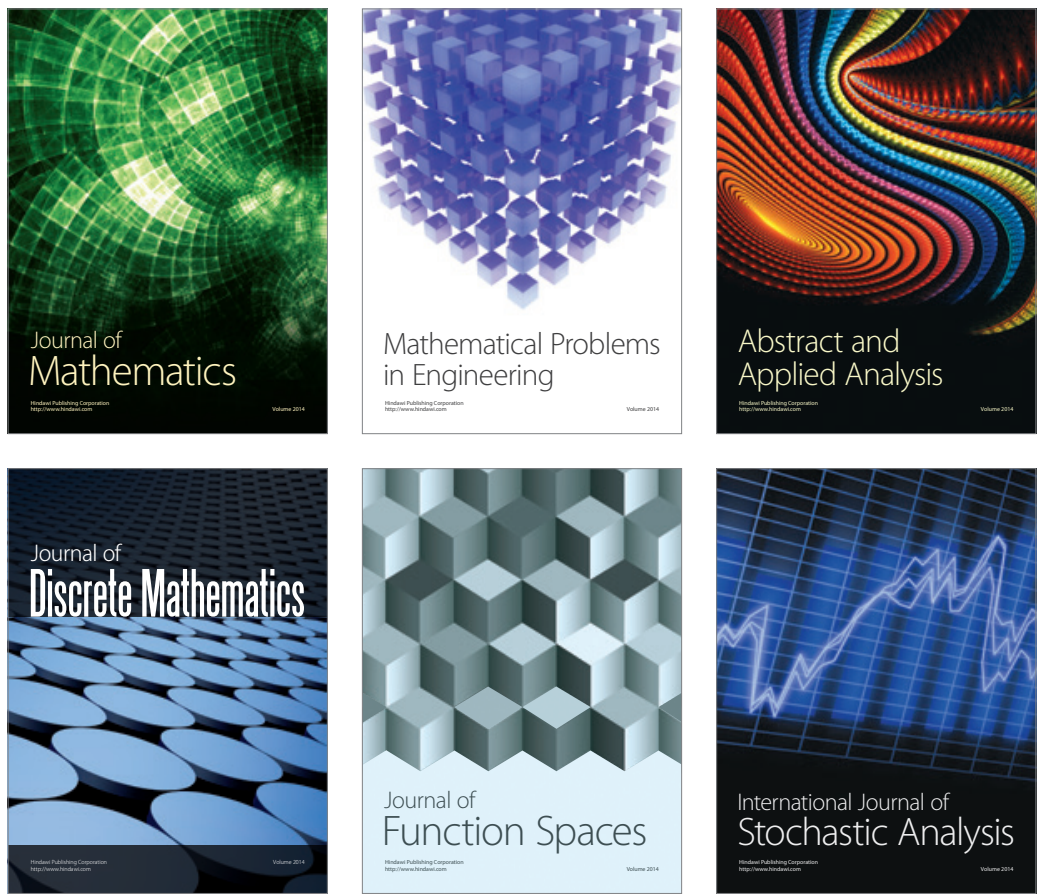

Journal of

Function Spaces

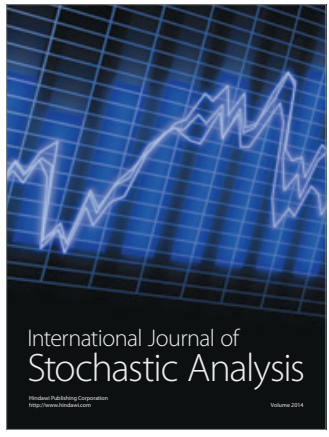

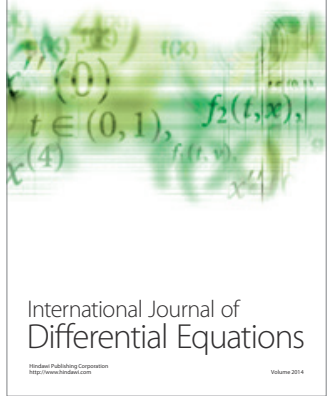
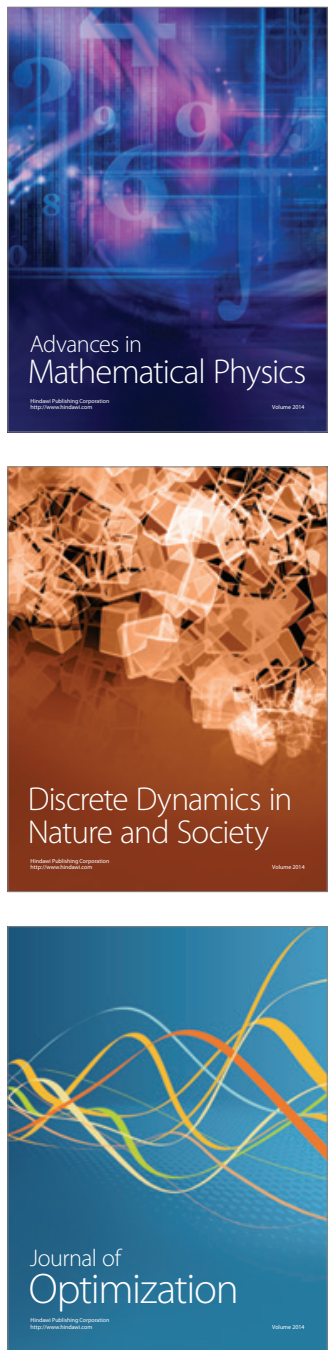